these are numbers expressed in relation to the total background population. In the example quoted (Table II), crude rates have been calculated by dividing the number of admissions by the total catchment population and expressed as a rate per 100.000 . They are not based on the age or sex structure of the population under study.

TABLE II

Population structure and ps.ychiatric admissions in Nottingham (1981)

\begin{tabular}{|c|c|c|c|}
\hline \multicolumn{4}{|c|}{ Nottingham's population: } \\
\hline \multicolumn{3}{|c|}{ Persons aged under 15} & 80.000 \\
\hline \multicolumn{3}{|c|}{ Persons aged $15-64$} & 245,000 \\
\hline \multicolumn{3}{|c|}{ Persons aged $65 \&+$} & 55,000 \\
\hline \multicolumn{3}{|c|}{ Total population } & 380.000 \\
\hline \multicolumn{4}{|c|}{ Admissions - rates: } \\
\hline Age & $\begin{array}{l}\text { Number of } \\
\text { admissions }\end{array}$ & $\begin{array}{l}\text { 'Crude rates } \\
\text { per } 100.000 \\
\text { population }\end{array}$ & $\begin{array}{c}\text { 'Age specific rates' } \\
\text { per } 100.000 \\
\text { population }\end{array}$ \\
\hline $15-64$ & 1114 & 293 & 455 \\
\hline $65 \&+$ & 470 & 124 & 855 \\
\hline $15 \&+$ & 1584 & 417 & $\overline{528}$ \\
\hline
\end{tabular}

Crude rates summarize population characteristics in a single figure and have the advantage of allowing the reader to add such rates in the same way that the actual numbers upon which they are based can be added.

Further, when the age structure of a given population is either unknown or unimportant, crude rates may be suffciently descriptive. For instance, when examining patient prevalence in a general psychiatric service covering the whole age range, they will usually provide an adequate picture of the uptake of services.

\section{Specific rates}

Specific rates take account of demographic details such as sex and age (for the purpose of this paper, we will discuss age specific rates only). As mentioned above, such rates consider information in relation to the underlying population for any given study. They permit the user to compare areas of different size and population structure. Although age specific rates are more tedious to compute. they yield more information and are particularly useful when examining specific age groups, for instance in the planning of services for adolescent or elderly populations.

The example quoted previously shows the numerical differences between using crude and specific rates, and highlights the importance of understanding which particular type of rate is being applied. Although numerically the elderly (aged 65 and over) have fewer admissions, it is apparent that they have a greater likelihood of being admitted than those aged under 65 . In fact an elderly person is almost twice as likely to have an in-patient admission. This cannot be deduced from crude rate statistics.

As a further example of the difference between the two forms of rates discussed, let us assume that the population structure of Nottingham is different, as shown below:

\begin{tabular}{lr} 
Persons aged under 15: & 80.000 \\
Persons aged 15-64: & 200.000 \\
Persons aged 65 \& +: & 100.000 \\
\cline { 2 - 2 } & 380.000
\end{tabular}

As the total population in the above has not changed. the crude rates remain unaltered. However, as age specific rates take account of the underlying population structure. they become:

$\begin{array}{cccc}\text { Age } & \text { No of admissions } & \text { Age specific rates } \\ 15-64 & 1114 & 557 & (455) \\ 65 \&+ & \frac{470}{1584} & \frac{470}{528} & \frac{(855)}{(528)}\end{array}$

(Specific rates from previous example in parentheses.)

In summary, if a population's structure is known, then one can apply either crude or age specific rates. If, on the other hand. the size of the population is known but not its constitution, then the application of age specific rates is not possible-in such cases only crude rates can be employed. and only limited conclusions can be drawn from the information.

An understanding of the appropriate use of rates is relevant not only to clinical and epidemiological investigation, but also to planning and monitoring of health services. Efficient planning depends on the availability of detailed information about the services being offered as well as the population being served. It is hoped that the above notes go some way toward encouraging the effective use and interpretation of numerical data.

ACKNOWLEDGEMENTS

The Nottingham Psychiatric Case Register is supported in part by a grant from the Department of Health and Social Security. We are grateful to Mr K. D. Bledin and Professor J. E. Cooper for their advice and assistance.

\title{
B. B. Zeitlyn Psychotherapy Training Fund
}

A fund has been set up for those living in Cambridge and East Anglia who wish to train as psychotherapists. Monies are available as an interest-free loan to be repaid within three years of completion of training.

Applications must be received by 22 April 1985 and loans to successful applicants will be offered from 1 October 1985. Those interested should write for further information to: Honorary Secretary. Gaye Jurewicz. 16 Milner Road. Comberton. Cambridge CB3 7DE. 